\title{
Estrangeiridade e Vulnerabilidade Psíquica: Algumas Contribuições Psicanalíticas
}

\author{
Suzana Duarte Santos Mallard ${ }^{1}$ \\ Maria Virginia Filomena Cremasco \\ Universidade Federal do Paraná \\ Jean Claude Metraux \\ Université de Lausanne
}

\begin{abstract}
RESUMO - Para discutir algumas contribuições que a perspectiva psicanalítica traz para a compreensão da condição de estrangeiridade, entrevistamos um grupo de estudantes vinculados a programas de formação superior vindos de países de língua oficial portuguesa. Organizamos, a partir da análise das unidades de significado das entrevistas, alguns dos conflitos experimentados. Além da língua, os motivos da escolha do país, a chegada, a integração, o convênio, os relacionamentos afetivos e sexuais, a percepção dos brasileiros e a percepção das dificuldades encontradas compõem o cenário que possibilitou nossa leitura. O sofrimento que alguns demonstram mais do que outros, diz de um conflito que é próprio da constituição do sujeito e que pode emergir nessa experiência.
\end{abstract}

Palavras-chave: estrangeiridade, língua, intercâmbio, psicanálise, sofrimento

\section{Foreignness and Psychic Vulnerability: Some Psychoanalytic Contributions}

\begin{abstract}
The purpose of this paper is to discuss the contributions that a psychoanalytic perspective might bring to understand the condition of foreignness. To achieve this we interviewed a group of students linked to the higher education programs from countries whose official language is Portuguese. The analysis revealed that foreignness can be experienced by the subject as a conflict inherent to its nature: the helplessness facing everything that is unfamiliar may be reinforced in case of the contradiction of the "same" language spoken. The subjects referred to certain conditions and experiences of foreignness that may hinder the acceptance and identification with the new culture: the reasons for the choice of Brazil, the arrival, integration, school partnership, affective and sexual relationships, the perception of Brazilians and the difficulties encountered. From this emerges a vulnerability of the psychic sphere that reveals the deconstructive potential realized only when it occurs.
\end{abstract}

Keywords: foreignness, language, exchange programs, psychoanalysis

"O estrangeiro sempre faz mal àquele que recusa a interrogação", escreve Enriquez (1988, p. 40). O que é esse olhar que nos convoca em um lugar estranho onde não passamos de estrangeiros diante do que não mais se mostra familiar? Um olhar estranho, um estranho olhar, o olhar do estrangeiro, um olhar estrangeiro. O lugar que se pode ocupar, do qual se olha o outro parece estar vinculado ao conjunto de obrigações culturais ao qual estamos submetidos e à organização psíquica que somos capazes de construir.

Os primeiros intercâmbios aconteceram a partir de 1940, durante a II Guerra Mundial. Após a experiência em zonas de conflito, alguns grupos quiseram estabelecer uma proximidade com aqueles que lá estiveram. Na medida em que o valor dessa foi resgatado, a ideia dos intercâmbios começou a ser veiculada como uma oportunidade para propiciar a aproximação cultural.

O objetivo deste artigo é o de discutir as contribuições que a perspectiva psicanalítica pode aportar para a compreensão da condição de estrangeiridade, através da pesquisa de Mestrado em Psicologia da UFPR. Nesta, por intermédio da escuta de estudantes vinculados a programas de intercâmbio através de algum convênio de ensino superior oriundos de países de língua portuguesa, pudemos ter acesso aos relatos dessa experiência. Com a pesquisa foi possível identificar

1 Endereço para correspondência: Rua General Glicério 126, Apto.601, Rio de Janeiro, RJ, Brasil. CEP: 22245-120. E-mail: suzana.dsm@ gmail.com as queixas de alguns dos estudantes a respeito da condição de estrangeiro. A escolha desse grupo específico se deu a partir da hipótese de que compartilhar do "mesmo" idioma poderia ter implicações específicas que não as mesmas da vivência de um estrangeiro cuja língua oficial não é o português. Falar português no Brasil faz com que, perante os brasileiros, não seja reconhecido seu estatuto de estrangeiro. A aparente facilidade em falar a mesma língua logo se mostra pouco facilitadora para esses sujeitos quando em condição de estrangeiros. A partir das contribuições da psicanálise foi possível estabelecer uma diferença entre ser estrangeiro e estar em condição de estrangeiridade. Essa condição de estrangeiridade diz respeito àqueles sujeitos cuja condição de estrangeiro implica queixas referentes aos efeitos do encontro intercultural. Efeitos esses que podem assumir o valor de um sofrimento psíquico. A estrangeiridade é entendida aqui como uma condição implícita da constituição humana experimentada por todo sujeito em momentos específicos, ao longo de sua vida. O enunciado freudiano "o eu não é senhor em sua própria casa” (Freud, 1917/1987, p. 178) ilustra com pertinência a ideia que norteou nossa investigação: o sentido que atribuímos ao conceito de estrangeiridade em nosso trabalho. No entanto, a maneira como o ego opera diante de uma condição de estrangeiridade denuncia uma crença implícita de que o sujeito se acomoda diante do que lhe é familiar. A pessoa em questão está certa de ter o controle 
sobre seu próprio corpo, suas reações e o mundo que habita. É essa certeza que a condição de estrangeiridade abala, nega.

A inconsistência das certezas e a consciência de não ter mais garantias a respeito dessas, deixa o sujeito potencialmente vulnerável. Uma vulnerabilidade que é a possibilidade à condição de estrangeiridade. Aquela que faz determinada pessoa experimentar certo desamparo diante do que não é reconhecido como familiar. Compreende-se que de alguma forma existe na condição de estrangeiro, a possibilidade de se ocupar um lugar de uma angustiante interrogação diante do outro. Esse lugar é singular/único. No entanto não é em todas as situações que é possível falar de estrangeiridade. A condição da estrangeiridade está vinculada a uma vulnerabilidade que não necessariamente é vivida por todo estrangeiro.

Circulamos o tempo todo por espaços que evocam em nós este estranhamento que é característico do olhar estrangeiro. Pensar no conceito de estrangeiridade enquanto condição de estranhamento diante de um confronto de realidades, ajuda a ampliar a noção que podemos ter da mesma. Olhamos, estranhamos, comparamos, identificamos e nos acomodamos novamente na familiaridade daquilo que reconhecemos em um tempo próprio de cada sujeito. Assim, estrangeiridade é entendida como um lugar que todos podem ocupar em um momento ou outro da vida, porém com implicações subjetivas particulares de cada sujeito em função de sua história. Às vezes nos vestimos de um olhar que não distingue na cena que presenciamos os objetos e suas funções, nem como se incluir nela. Somos estrangeiros desde que nascemos, na medida em que ocupamos lugares estranhos em que não parece haver um enodamento com a cena. Se em um segundo momento podemos reconhecer algum laço social e atribuir um valor ao vazio que permeia a realidade é por que pudemos perceber uma estranheza nesse lugar onde o vazio irrompe. O que se torna familiar se dá numa cena na qual nossa experiência acontece. Diante das cenas nas quais a familiaridade orienta a ação, a experiência a ser vivida pode ser entendida como programada, na medida em que existe uma noção da cena e das consequências de nossas ações dentro dela. Ou seja um ambiente previsível e controlável dentro dos limites culturais conhecidos.

Estranho para Freud (1919/1987) relaciona-se com o que é assustador. As coisas "estranhas" são aquelas que estão dentro do campo do que é ameaçador. O estranho em Freud, não é novo ou alheio ao sujeito, diz respeito a algo que é familiar (das Heimliche). O retorno do recalcado emerge como sintoma na medida em que a familiaridade alienada através da repressão estabelecida no inconsciente opera como seu oposto, estranho (das Unheimliche). O que não é familiar é tudo aquilo que permanece inconsciente no universo psíquico e que remete àquilo que não se pode compartilhar com a comunidade. A estrangeiridade é, portanto, o que emerge como sintoma - o retorno do recalcado.

Poder reconhecer o que é estranho, é também admitir o que é da ordem da diferença. Não reconhecer a diferença legitima atualmente a exclusão e falta prática de ações dirigidas para esse esses estudantes.

O percurso bibliográfico nacional que permeou essas articulações traz como importante contribuição as investigações da Caterina Koltai cujos textos articulam e enfatizam a psicodinâmica do vivido na experiência da estrangeiridade. Em "Política e Psicanálise" (2000), a autora explora, a partir de conceitos psicanalíticos, a condição de "estrangeiro", enquanto conceito-limite entre psicanálise e política, entre a psicanálise e as ciências humanas. A figura do estrangeiro é descrita pela autora como aquele que se encontra na fronteira do sujeito singular com o social, apontando em parte o que esta exclusão mascara: uma exclusão em decorrência do que o estrangeiro representa, o limite entre eu e nós. Também incluímos o texto "Intercâmbio Cultural", da psicóloga Andrea Sebben (2000), cuja contribuição prioriza a caracterização, descrição e histórico do intercâmbio.

Abordamos - além dos aspetos referentes à dinâmica social no qual o sujeito migrante não se insere, isto é, o que ele representa para quem "acolhe"- também a psicodinâmica daquele que "escolhe" migrar e seus efeitos. No entanto, fizemos a escolha de escrever a respeito daquilo que para o migrante, o estrangeiro em condição de estrangeiridade, emerge enquanto questão de identificação, de reconhecimento e da língua. Para leitura do contexto local, foi necessário contar com autores que descreveram o conceito de estrangeiridade em diferentes cenários, a partir de seu próprio contexto cultural. Recorremos à Okba Natahi que em seu livro "Dinâmica do aberto e problemática do estrangeiro" (2007) discute a experiência do estrangeiro que migra. Nessa experiência, o imigrante parece questionar-se com frequência a respeito de suas próprias ficções simbólicas a partir do confronto entre o familiar e o estranho. As ficções simbólicas são consideradas elementos que garantem o estabelecimento do vínculo do sujeito com sua comunidade de origem e permitem a repetição das experiências programadas. No entanto, o que é vivido pelo estrangeiro como o sintoma de uma foraclusão é entendido aqui como produção da atualidade na qual vigora a ideia de uma comunidade compacta sem diferenças. René Kaës (1998) trata desse assunto em "Différence Culturelle et souffrance de l'identité", apontando para a possibilidade de uma correlação entre sofrimento identitário e diferença cultural. Poderíamos, assim, inferir que um sofrimento pode emergir também do confronto entre identidade e diferença. Esse sofrimento, advindo de um estado descrito como "limite", encontra sua consistência teórica no campo da psicanálise no conflito entre o imaginário e sua projeção de laço com o outro, isto é, entre o ego ideal e o narcisismo. O sofrimento do "estado limite" em que a estrangeiridade coloca o sujeito é, antes de tudo, uma patologia do ego pelo próprio papel que ele desempenha, uma instância que detém um ideal que é confrontado a todo o tempo com um real. O sofrimento que diz respeito ao ego ideal está com frequência em primeiro plano no discurso daqueles que se encontram no estado limite, na condição de estrangeiridade. Mesmo não se manifestando, os conflitos do superego também continuam presentes.

Essa condição clínica e teórica sinaliza de certa maneira um mal-estar característico da condição de estrangeiridade, uma subjetividade em contínua tensão entre ideal de ego e o ego ideal. Um conflito interno que denuncia a introjeção de um esquema de relações na qual, por um lado, aparece o ego falho e, por outro, o superinvestimento no ego que resulta numa certa hemorragia narcísica, como descreve Kaës (1998). A conquista e transformação que todo o confronto cultural 
convoca é sentido como ameaçador, pois nas migrações, a língua de transmissão materna deixa de operar temporária ou definitivamente. No grupo de pesquisa específico de estudantes oriundos de países de língua portuguesa pudemos registrar um sofrimento dessa ordem, diretamente vinculado à língua, pois a língua portuguesa falada em diferentes países não é a mesma língua. A esse respeito sabemos que a cultura tem o papel de introduzir o sujeito na ordem e organização de sua língua. É através dela que se dá a transmissão da cultura. Toda sociedade tem sua própria maneira de transmitir a seus integrantes seus valores. Em um primeiro momento essa transmissão se dá através dos cuidados com o corpo, o qual, a partir disso, torna-se pulsional. O psiquismo constitui-se a partir desse encontro entre um corpo e Outro que nele investe. A palavra acompanha esse primeiro investimento nesse corpo para se tornar a via primordial da transmissão dos valores e das interdições de uma cultura. Essa palavra, a língua materna, acompanha todas as ações e se inscreve no corpo da criança, mesmo antes que domine essa linguagem, uma transmissão que garante a sobrevivência da memória coletiva, a construção e o registro da memória individual que possibilita a constituição do superego. No entanto a cultura não é uma entidade estanque, ela está em constante transformação como o ser humano que a constrói. O sujeito é subordinando a um sistema de significações no qual suas palavras ganham sentido e lhe atribuem um lugar. $\mathrm{O}$ conceito de cultura é entendido aqui como aquilo que nos é transmitido, que é incorporado e introjetado desde o laço primário, com seu sistema de representações e relações identificatórias. Nem o sistema de significações, nem o lugar e nem a língua são as mesmas para o grupo pesquisado. A experiência de intercâmbio pode ser comprometida pela condição de estrangeiridade que ela introduz diante da ausência do reconhecimento da falta desses elementos na cena e sua complexidade, condição essa que, na diferença cultural, confronta o sujeito com uma situação totalmente desconhecida e que pode ser vivida como ameaçadora.

Falar de estrangeiridade é falar da identificação com o outro que perde sua consistência. É falar de uma falta que parece ameaçar o próprio ideal de ego. Quando o estrangeiro fala uma língua diferente daquela do país que o acolhe, as implicações perante seu estatuto parecem conceder-lhe um lugar diferente daquele que fala a "mesma língua". Os estudantes oriundos de países de língua oficial portuguesa não são considerados tão estrangeiros como aqueles que falam outra língua. Deles espera-se de imediato um saber a respeito da língua que nega as diferenças que essa carrega.

A língua oficial dos países dos participantes da pesquisa é português. Por língua oficial entende-se uma língua que tem seu uso amparado pela lei que garante que ela seja adotada nos eventos oficiais e em comunicações formais que ocorrem no país. Dentre os estudantes que participaram da pesquisa havia estudantes de Angola, Cabo Verde e Guiné Bissau, países de língua oficial portuguesa. Outros países de língua oficial portuguesa mantêm convênio com o Brasil: Moçambique, São Tomé e Príncipe e Timor Leste. Não tivemos participação de estudantes dessas proveniências, no entanto estendemos nossa compreensão do fenômeno da língua estrangeira também a eles. Mesmo tendo como língua oficial o português, os estudantes costumam usar outras línguas como forma de comunicação mais corriqueira.

Os outros idiomas que não a língua oficial são as primeiras línguas de transmissão primordial, podendo portanto ser consideradas como línguas maternas, pois a língua portuguesa é aprendida apenas na escola. O português é uma herança da colonização de Portugal e é utilizado como o idioma das formalidades. Quando se fala com o colega que possui a mesma origem, que é da mesma tribo, utiliza-se outra língua. Certamente ter um idioma comum trouxe benefícios econômicos e culturais entre os países, porém é necessário reconhecer a importância dos outros dialetos das diferentes regiões. Nos países que foram colônias portuguesas, além do português oficial, falam-se muitos outros idiomas. Em Angola existem mais de 42 línguas consideradas pelo estado como dialetos, através dos quais acontecem as transmissões geracionais. Dentre os principais estão o umbundo, quimbundo, quicongo, ovimbundo e bacongo. Nas ilhas de Cabo Verde, também país de língua oficial portuguesa, a realidade não é muito diferente da de outras antigas colônias. Das 10 ilhas que compõem o país, nove são habitadas e nelas fala-se o crioulo. No entanto, existe uma diversidade ainda de crioulos entre as ilhas. Guiné-Bissau é um país da costa ocidental da África que, além do território continental, integra as o Arquipélago dos Bijagós com cerca de 80 ilhas. Na Guiné, $60 \%$ da população fala o kriol cujo vocabulário vem em sua maioria da língua portuguesa, sendo o mais antigo das línguas crioulas com essa origem. Além da Guiné, essa língua é falada no Senegal e adotada como primeira língua por cerca de 160 mil pessoas e como segunda língua, por 600 mil. Em Guiné-Bissau, somente 13\% da população fala português. Existem nesse país três outras línguas principais o bafatá, bolama e bissau, cacheu-ziguinchor com origem em povos próximos, os mandingas, manjacos e papéis.

Cerca de metade dos países do mundo tem línguas oficiais expressas na lei, alguns têm uma língua oficial outros têm mais de uma. Para alguns dos estudantes, o português pode ser considerado como a sua segunda língua, pois passou a ser aprendido e falado com o início do ensino fundamental. Consideramos, dessa forma, o português um idioma estrangeiro como tantos outros que se aprendem ao longo da escolaridade. O português não se limita a ocupar o lugar de uma língua estrangeira como as outras, ele é também carregado de outras conotações implícitas que criam neste contexto de estrangeiridade alguma dificuldade. A língua portuguesa aparece em diversas esferas públicas e administrativas no país em que é tida como língua oficial. É compreendida pelos membros da comunidade e é obrigatório se fazer uso dela para que as solicitações sejam reconhecidas.

Quando se fala uma língua que não é a materna, com frequência existe um distanciamento, uma déconnexion [desconexão] (Kaës, 1998, p. 107) de si mesmo e uma diminuição do grau de intimidade entre palavras e coisas, conflitos e suas expressões e representações; é difícil expressar seu sofrimento numa língua que não se domina. Segundo Kaës, no encontro intercultural existe um papel importante do pré-consciente em relação à língua estrangeira. Na encenação da representação da palavra, isto é, na tentativa de fala, de transmissão, quando um não entende a língua do outro, o que acontece é um fracasso momentâneo da 
atividade do pré-consciente. A finalidade desse é criar uma interpretação do externo para interno, para que aconteçam as representações inconscientes. A expressão e descargas de afeto em palavras encontram-se prejudicadas quando não se domina uma língua, o que gera angústia.

As dificuldades que não se restringem ao campo psíquico têm consequências também no âmbito acadêmico. A respeito da língua portuguesa, existe um longo debate sobre a unificação da mesma nos países nos quais esse é o idioma oficial. No entanto, essa discussão está longe de acabar. Existem duas ortografias reconhecidas na língua portuguesa, o que dificulta sua aceitação internacional. Dessa forma, as comunidades que falam esse idioma buscam uma unificação através de um debate que vem acontecendo há mais de 15 anos. Sobretudo no meio acadêmico, a possibilidade dessa unificação tem sido alvo de preocupação. É uma tarefa difícil e polêmica avaliar o que é correto ou o que não é na escrita portuguesa a partir do simples pressuposto de que, dependendo das necessidades, ela pode evoluir e ser alterada ao longo do tempo. Muitos acordos e desacordos alongaram a decisão da unificação que se concretizou finalmente com o Acordo Ortográfico da Língua Portuguesa, em vigor desde o inicio de 2009 no Brasil e em 13 de maio de 2009 em Portugal. Foi estabelecido que cada país teria um tempo de transição até as reformas serem validadas e incorporadas, três anos para o Brasil e seis anos para Portugal e para as antigas colônias. Mesmo com um acordo firmado, muitos portugueses se recusam a adotar as regras da reforma dizendo se tratar de uma simplificação que só beneficia o Brasil. A questão está longe de ser resolvida e uma solução exige esforços que apontem acordos que tragam benefícios para todos, acima de interesses políticos das comunidades. Mesmo assim dificuldades permanecem. Ainda que consideremos a língua portuguesa falada em Portugal como uma língua estrangeira, reconhecemos que existe uma maior familiaridade diante dela do que do português do Brasil para os estudantes oriundos dos países de língua oficial portuguesa. Quando esses chegam ao Brasil e escrevem utilizando o português oficial de Portugal, são frequentemente criticados pelos professores que apontam sua dificuldade de compreensão. É-lhes solicitado que assimilem rapidamente a gramática e o vocabulário brasileiro para iniciar sua produção acadêmica. A forma como cada um aprende e integra esse "novo" português vai da iniciativa de cada estudante. Em um tempo de adaptação próprio de cada estudante, essas produções começam a apresentar mudanças, resultando em tentativas mais ou menos bem sucedidas. $\mathrm{O}$ que foi exigido em seus países até então, enquanto acordo linguístico formal, passa a não ter mais valor no país de migração.

Nessa discussão, a língua representa um importante papel, pois é o que caracteriza e restringe o grupo objeto de pesquisa. $\mathrm{O}$ fato de não se falar o mesmo português, de não poder produzir em seu próprio português, de seu idioma ser considerado estrangeiro, além das implicações psíquicas, certamente tem um peso na experiência do intercâmbio desses jovens.

Entende-se que ocupar - diante do olhar do outro um lugar ou outro/um devido lugar, resulta em diferentes implicações subjetivas. É necessário poder dar a palavra a esse migrante e que ele coloque em palavras as implicações de ser um estrangeiro que fala português no Brasil.

$\mathrm{O}$ crescente número de estudantes que aderem a esse tipo de programa possibilitou a emergência e a visibilidade dos impasses próprios de um confronto cultural. A partir da psicanálise, que valoriza a experiência individual, é possível restituir a esse fenômeno toda a sua complexidade sem reduzi-lo a uma generalização.

\section{Método}

Este estudo foi o resultado de uma pesquisa na qual foi apresentado um questionário com quatro questões abertas a serem respondidas pelos estudantes individualmente. As perguntas retratam momentos diferentes da vida do estudante.

A delimitação dos fatores mais frequentes e preponderantes foi identificada a partir da análise qualitativa. Essa etapa limita as generalizações, constituindo-se em uma análise que privilegia as percepções pessoais e as interações entre os diversos níveis. As respostas foram confrontadas, permitindo caracterizar os conflitos não percebidos, mas explicitados a partir de respostas aparentemente contraditórias. A análise de cada resposta ou grupo de respostas permitiu consolidar as características do grupo investigado.

\section{Resultados}

Segue o agrupamento por temas composto pelas respectivas unidades de significado que constituem o material de pesquisa:

- Motivo da escolha pelo Brasil: Nesta unidade reunimos todas as falas dos participantes que se referem a esse tema.

$\underline{\mathrm{R}}$ : "Me senti motivado para estudar no Brasil por questão da facilidade linguística e pela realidade cultural "similar". A cultura brasileira tem algumas semelhanças com a cultura de países africanos lusófonos. Meu irmão estudava aqui pelo PEC-G." D: "Sempre quis estudar fora, no primeiro momento quis estudar em Portugal porque tenho família, parentes, tentei várias vezes, em 2001, 2003 e 2004; não consegui nenhuma das vezes mas consegui vir para o Brasil". M: "Escolhi o Brasil devido à proximidade cultural. Temos uma identificação com os brasileiros. Pesquisei várias cidades onde poderia ir, mas um amigo que fazia filosofia aqui na Federal (UFPR) me mandou um e-mail com uma descrição muito incentivadora da cidade de Curitiba, que me motivou a vir para cá."

- Chegada ao Brasil: Os alunos chegaram no Brasil em momentos e condições diferentes, suas experiências e relatos são únicos. Alguns estudantes estavam no Brasil há mais tempo do que outros e suas lembranças foram distintas. $\underline{E}$ : "Cheguei sozinho, não fui recebido por ninguém. Pedi para o taxista me levar para o primeiro hotel que tivesse. No dia seguinte pedi que me levasse para perto da Federal (UFPR). Ele me levou para a Casa do Estudante e fiquei lá como visitante por uma semana." $\underline{\mathrm{U}}$ : “Cheguei ao Brasil quando as aulas já haviam começado. Vim por conta própria, não sou bolsista. Tinha uns conhecidos na cidade, mas tive que fazer as coisas sozinho." $\underline{\mathrm{H}}$ : "Fui recebido por uma amiga 
da família que logo me levou para uma churrascaria. Essa pessoa me esperou no aeroporto. Estou aqui há mais de três anos. Está tudo correndo bem."

- Integração: O objetivo dessa unidade de significado foi o de evidenciar se ocorreu, e de que forma, para os diferentes participantes, uma integração na cultura e nos grupos locais, além da vivência acadêmica. A. "Eu demorei mais ou menos um ano para me acostumar. Não gosto de Portugal, mas não conheço. O povo de lá é fechado, aqui é mais fechado ainda. Perdi muita coisa no primeiro ano, só no segundo fui me enturmar." $\underline{\mathrm{U}}$ : "Tivemos problema para conseguir onde morar. Ficamos na Casa do Estudante. Agora estou achando aqui tranquilo." $\underline{\mathrm{H}}$ : “A adaptação foi fácil. Não consigo falar com sotaque brasileiro. Estou aqui há mais de três anos. Eu não tive muitos problemas. Deu muito certo com as pessoas daqui. A escolha foi planejada com meu pai. Eu já tive outras experiências em outros países."

- O convênio: questões específicas relatadas pelos estudantes integrantes de programas de convênio assim questões práticas, burocráticas, culturais e acadêmicas foram tratadas aqui. M: "Na minha ilha o IRA [Índice de Rendimento Acadêmico] é muito importante. Tem que ter média acima de 12 para entrar numa universidade. Para conseguir bolsa tem que ser superior, acho, 14 ou 15. (...) A primeira coisa que nos dizem quando vimos pra cá é que estamos pegando a vaga de um brasileiro, pois nem sequer prestamos vestibular. Mas existe um método de seleção." E: "De certa forma acontece com a gente o que acontece com as pessoas que entram por cota. São vistas como inferiores. Mas são somente as melhores notas de Cabo Verde que são escolhidas para entrar aqui [no Brasil] numa Federal." $\underline{\mathrm{R}}$ : "É, mas não somos necessariamente os "melhores" de lá, pois isso também depende de condições financeiras, não só de dedicação."

- Relacionamentos afetivos e sexuais: Nesta unidade foram incluídos todos os relatos que retratam da vida afetiva dos estudantes. A partir delas é possível saber o modelo de relacionamento amoroso e/ou sexual vivido na época da pesquisa. L $\underline{\text { : }}$ "Eu não namoro aqui. De onde venho não tem isso de "ficar", o namoro lá é sério. Pra mim foi um choque isso." $\underline{\mathrm{R}}$ : "Tenho uma filha com uma brasileira e transmitimos um pouco de cada cultura. Mas só falo português com ela." Z: "Eu e meu marido tentamos passar um pouco de tudo que passamos, mas não tentamos forçar nada específico."

- Percepção dos brasileiros: Aqui foram registradas as falas dos estudantes que se referem à forma como os brasileiros são percebidos pelos estrangeiros. A partir delas é possível inferir sobre expectativas que existiram sobre a condição que se viria a ocupar enquanto estrangeiros frente aos brasileiros. E: "A gente não quer ser visto enquanto estrangeiro, a gente quer ser tratado como todo mundo, mas tratado como estrangeiro no sentido de saberem a diferença da nossa cultura." $\underline{\text { A: }}$ "Eu pensei que o Brasil fosse o que se passa nas novelas, mil maravilhas, e quando eu cheguei aqui eu vi que é totalmente diferente, principalmente aqui em Curitiba." E: "É verdade, vocês valorizam estrangeiro, mas não valorizam o que tem aqui. Não falo mal da cidade, porque me acolheu."

- Estrangeiridade: O objetivo desta unidade é apresentar falas que, de alguma forma, pudessem ser vinculadas ao conceito de estrangeiridade conforme percebido no presente trabalho, enquanto: um lugar de perda indenitária, mesmo que temporária. $\mathrm{D}$ : "O isolamento acaba deprimindo a gente um pouco." $\underline{\mathrm{R}}$ : "É preciso entender que tem uma identidade por trás do sujeito. Fiz uma prova onde perguntava sobre a ginga brasileira. Nem mesmo o professor sabia me explicar o que era. É preciso considerar essas diferenças sintáticas e de significado." L: "Perdi rendimentos na faculdade. Sintome sozinha aqui, eu trabalho e estudo, ninguém da família pode me ajudar."

- Diferenças culturais: Unidade dedicada aos relatos que se referiram às diferenças culturais que foram percebidas pelos estudantes intercambistas com relação à cultura curitibana. R: "Lá nós vivemos muito em comunidade, até porque o país lá é pequeno." E: "É uma crença de lá de que depressão é frescura." A. "Lá eles acham que ir ao psicólogo é frescura."

- Dificuldades: Nesta unidade compilamos a sequência de dificuldades relatadas pelos estudantes com relação ao fato de serem estrangeiros, dificuldades essas que apareceram em diferentes âmbitos e com graus de importância variável entre os participantes. $\underline{\text { M: }}$ "Minha maior dificuldade foi a questão do idioma. Me "zoavam" por conta do meu sotaque. A alimentação e música também." A A: "Uma das coisas que mais nos prejudicou foi a escrita. A fala a gente até consegue pegar, mas a escrita é mais complicada. E olha que eu escrevo relatórios desde o segundo período." L: "Mais difícil é a saudade. Gostaria que o tempo corresse rápido para poder voltar."

Das falas apresentadas, percebemos que a escolha de estudar no Brasil é diretamente vinculada à ideia de uma proximidade cultural e linguística, o que não se confirma necessariamente na prática. A proximidade cultural, mesmo existindo, não é garantia de aceitação do estrangeiro. Os estudantes carregam em suas ideias pré-concebidas dos brasileiros, estereótipos vinculados a uma representação veiculada pelas mídias. Aqueles estudantes que escolheram Portugal num primeiro momento e que não foram aceitos, optaram pelo Brasil pela facilidade em conseguir vagas nas instituições de ensino superior. Isso diz respeito sobretudo aos estudantes de convênios formais como o PEC-G, o mesmo não se aplica aos estudantes que vêm por conta própria tentar uma vaga. Existe também uma categoria de estudantes que escolhem o Brasil em primeiro lugar, pois não simpatizam com a cultura portuguesa em si. Um aluno falou a respeito da frieza dos curitibanos, pois havia uma expectativa em relação ao que seria o acolhimento dos brasileiros para com os estrangeiros. As mídias transmitem parte da programação televisiva brasileira, nos países que foram colônias portuguesas. A imagem veiculada é a das novelas ou os reality shows e programas sensacionalistas. A partir de uma ideia construída e idealizada a respeito dos brasileiros, uma generalização, esses estudantes tiveram um verdadeiro choque cultural. A frieza atribuída aos portugueses foi encontrada em Curitiba. No entanto, a construção da imagem dos portugueses não se resume a um único fator. $\mathrm{O}$ fato de não simpatizarem com a cultura portuguesa diz respeito à própria história da recente descolonização. Os portugueses, hoje, dentro uma política de neocolonialismo, ocupam lugares de destaque no controle das economias 
dos países que foram colonizados. Mesmo diante dessa realidade, Portugal dificulta a entrada de africanos no país e mantém políticas de exclusão daqueles que já se encontram lá. Entre todos parece haver o consenso de que existe uma proximidade entre seu país e o Brasil, essa poderia se traduzir em acolhimento, o que não acontece na realidade. A boa imagem dos brasileiros foi exacerbada em detrimento da generalização da má imagem dos portugueses.

Podemos claramente dividir a experiência da chegada ao Brasil em dois tipos. Aqueles que chegaram sem ter alguém conhecido na cidade que o acolhesse e mediasse o confronto das diferenças entre as culturas, relatam uma experiência difícil e até mesmo dolorosa. Aqueles que chegaram tendo alguém a sua espera, ou simplesmente uma referência de sua própria origem e que pudesse orientar a descoberta do novo universo cultural, puderam viver o momento com mais tranquilidade.

Entre trâmites burocráticos dá-se o primeiro contato e choque cultural evocado pela própria condição de estrangeiro. Em um primeiro momento, a questão da moradia, mesmo que provisória, precisa ser resolvida. Casas de estudante, repúblicas, casas de família e até mesmo hotéis são os primeiros lares desses estrangeiros. O sucesso do encontro de uma moradia pode chegar entre muitas dificuldades. Logo acontece a passagem obrigatória pela Polícia Federal para legalização da estadia no país. Sem a legalização no país, os estudantes não podem estudar e nem alugar imóveis em seu nome como também abrir conta em banco ou até mesmo viajar. E logo precisam se matricular na instituição de ensino. Todos esses momentos podem acontecer numa ordem própria, mas nunca livres de estranhamento. Sem visto, não se pode obter um CPF (Cadastro de Pessoa Física), que é a prova de existência e regularidade fiscal, que serve para alugar, comprar, parcelar etc.

Para uma maioria a "integração" é difícil e aponta a falta de um dispositivo de recepção enquanto um agravante desse momento. $\mathrm{O}$ fato de os curitibanos serem pouco receptivos, ou frios, como os descreveu um aluno, tem seus efeitos. Aquilo que é da ordem das diferenças culturais pode assumir o lugar de estranheza. Com a falta de receptividade, alguns alunos perderam a oportunidade de ser introduzidos na cultura de maneira a minimizar o estranhamento das diferenças culturais. Alguns alunos demoraram mais tempo para conseguir se integrar e se aproximar dos colegas no primeiro ano de estudo. É comum entre os estudantes a queixa de terem perdido a oportunidade de vivenciar certas experiências que o intercâmbio poderia oferecer.

Os estudantes eram alvo de certo estranhamento da língua por parte das pessoas com as quais interagiam no dia a dia. A percepção de outro português resultava, segundo os estudantes, em admiração e curiosidade, ironias e piadas ou até mesmo rejeição. Em todos os casos, foi relatado que não eram compreendidos. Além de inúmeras exigências burocráticas, o próprio preconceito apareceu em várias situações como obstáculo. O racismo, a rejeição ao diferente aparecem ao longo da experiência, produzindo reações diversas por parte dos estudantes. Para alguns, ser o destinatário desse sentimento desencadeou um sofrimento que dificultou a construção de relações sólidas nas quais pudessem acontecer trocas, entre diferenças. Os estudantes que já vivenciaram uma experiência internacional ou seja, que haviam se confrontado com dinâmicas próprias da imigração, conseguiam reagir. Para alguns, as experiências internacionais vividas em outra ocasião parecem ter produzido certa resistência diante do lugar de estrangeiridade que poderiam vir a ocupar. Parar eles, o que é estranho vindo do outro pode ser interpretado como característica daquela cultura ou até mesmo da pessoa em questão. A capacidade de não tomar para si, ou até mesmo reduzir o olhar de estranheza advindo do outro, é uma habilidade que parecem ter adquirido. Mostram-se sem receio de serem percebidos como estrangeiros ou sem perceberem esse lugar como uma ameaça à sua identidade. $\mathrm{O}$ fato de poder reagir de forma menos sofrida diante dessa condição parece dizer respeito a um reconhecimento de um lugar que foi ocupado anteriormente. Dentre esses, alguns adquiriram o sotaque e o vocabulário brasileiro e outros não, de alguma maneira demonstrando uma permeabilidade maior ou menor à diferença. $\mathrm{O}$ fato de não sentirem suas identidades ameaçadas na medida em que a outra cultura é introjetada está diretamente vinculado à outra cultura.

\section{Discussão}

O lugar de estrangeiridade e as implicações dessa condição aparecem de forma diluída na demanda própria do sujeito que pouco tem relação com a experiência pesquisada, mas sim, com sua história de vida. Isto é, os efeitos desta possível condição estão muito mais ligados ao seu ideal de eu do que propriamente à experiência de estrangeiridade. Todo sujeito clama por reconhecimento, carregado da história que constitui aquele que demanda. Na pesquisa apareceram muitas queixas ligadas ao fato de ser estrangeiro, mas não foi possível afirmar se, entre eles, haveria alguém que estivesse naquele momento numa condição de estrangeiridade. Momento este que diz de um sofrimento agudo por uma perda referencial. As queixas mostraram um número maior de sujeitos resistindo e rejeitando do que introjetando e se ajustando, ou rejeitando parcialmente aquilo que dessas diferenças julgassem que não lhes caberia. Dos oito participantes, somente dois relataram que a experiência se deu sem percalços. A intensidade dos efeitos da experiência da estrangeiridade parece ter uma ligação com os motivos e o valor que a escolha da migração ocupa para o sujeito. Uma escolha na qual está implicada uma expectativa que pode se encontrar correspondida ou não. Perante o idioma também muitos dos estudantes acreditavam que o fato de se falar supostamente o "mesmo" português pudesse recriar rapidamente uma familiaridade que diluísse as diferenças e acelerasse a adaptação. Entretanto, parece existir um distanciamento à língua portuguesa que não parece ser capaz de veicular o que é da ordem do mundo intrapsíquico para aqueles que têm outro idioma como língua materna. Restanos a perspectiva de uma escuta que traga em evidência para o sujeito a possibilidade de se reconhecer em sua escolha para que recupere a autonomia em relação ao outro. Reconhecer seu papel na escolha da migração a descaracteriza enquanto uma obrigação e restitui ao sujeito um lugar diante dela e dos outros. Sem relativizar a importância da instituição diante 
desse grupo em particular - cujo objetivo é o de integrar o estudante à academia para que dela adquira conhecimentos necessários para uma intervenção local - acreditamos que poder oferecer um lugar de escuta nesse contexto é a única indicação concreta à qual se chega ao final deste trabalho. $\mathrm{O}$ desfecho da experiência é particular e a capacidade de resiliência, resistência psíquica que favorece a superação de dificuldades, se atém ao potencial desestruturante que a experiência representa para cada um e, consequentemente, sua capacidade de transformar o que o ameaça em ensinamento e experiência vivida. A capacidade de um sujeito de superar um evento ou não, só pode ser observada na medida em que esse se depara com tal evento, sem poder afirmar com toda a certeza que o que é desestruturante para uns também o será para outros. Para compreender sua complexidade, somente uma escuta é possível, ao modo do lema: cada caso é um caso.

$\mathrm{Na}$ condição de estrangeiridade, parte da própria identidade é perdida, uma perda que introduz o sujeito em uma espécie de luto diante do qual ele não será mais o mesmo. Com o retorno às origens, o lugar e o olhar não são mais o que eram, pois a perda é irreversível. A experiência pode ser nomeada de luto identitário e diz da possibilidade do sujeito ressignificar seu lugar no mundo. Ora, o processo de luto não se resume a uma aceitação, menos ainda a um percurso sinalizado para a ressignificação (Métraux, 2011).

Nesse processo, diante do qual a identidade sofre uma profunda transformação diretamente ligada à perda de suas referências fundadoras, o luto seria indicador de que o sujeito pode elaborar o vivido. Um aluno relatou ter sentido que, na ocasião de seu retorno ao país de origem, não conseguira parar de chorar, e comparou-se a uma criança. Em seu retorno, o sujeito parece ter tomado conhecimento do que havia perdido e do lugar que não poderia mais ocupar. As angústias atormentam e deixam esse que parte, inexoravelmente, descentrado de si mesmo.

A possibilidade de experimentar a condição de estrangeiridade não é exclusiva daqueles que partem de um lugar familiar para outro "desconhecido". Diz respeito também àquele que "acolhe" o estrangeiro. Trata-se de uma dinâmica na qual olhar e ser olhado se confundem. Em comum, aquele que olha e aquele que é olhado têm essa experiência que evoca um aspeto constitutivo de toda subjetividade, possível de ser vivenciada a todo momento. Aquele que estranha e exclui parece acreditar na possibilidade de unidade, como também aquele que parte, antes de deixar sua cultura. Acontece que, na experiência da estrangeiridade, o sujeito é confrontado com a impossibilidade dessa unidade, por preservarmos fundamentalmente na constituição do eu uma singularidade que é impartilhável. Não existe a possibilidade de uma unidade cuja prerrogativa seja uma fusão, mas há sim unidade possível na integridade da experiência, daquilo que nos mostra igual enquanto diferentes.

Diante disso, a condição de "estrangeiro" pode ser pensada na medida em que parece haver, por parte do sujeito, uma tentativa de constituir a unidade para sempre perdida ou nunca existida em nós, mas sempre fantasiada e desejada. A própria etiologia da constituição do sujeito determina que haja a suposição de uma unidade, na medida em que o infante observa o outro cuidador. $\mathrm{O}$ infante precisa acreditar nessa possibilidade de unificação, para sair da condição de objeto, para advir como sujeito. A presumida unificação que se dá na dimensão social de forma sintomática, nos permite reconhecer o "outro" que não pertence, na medida em que esta fortalece o que é da ordem do familiar e do grupo. Esse mecanismo dá-se pela condição repressora do ideal de ego, como instância de resistência contra tudo o que se apresenta como uma realidade possivelmente frustrante e ameaçadora à integridade do ego. $\mathrm{Na}$ condição de estrangeiridade, esta integridade do ego é abalada.

O sujeito, em sua experiência de estrangeiridade, se transforma, numa dinâmica de perdas e ganhos que passam a constituir sua maneira de se perceber, perceber e ser percebido no contexto social. Essa dinâmica pode ser traumática e trazer sofrimento para algumas pessoas que necessitam de seu tempo para ressignificar sua experiência. A possibilidade de ressignificar sua experiência pode ser nomeada de luto identitário, o que não significa resignarse a ela. Segundo Métraux (2011), o processo de luto não se resume a uma aceitação, menos ainda a um percurso sinalizado para a resignação. Nesse processo, diante do qual a identidade sofre uma profunda transformação diretamente ligada à perda de suas referências fundadoras, o processo de luto e sua superação seriam indicadores de que o sujeito pôde elaborar o vivido. Uma elaboração que passa pela palavra e, nesse caso, pressupõe justamente falar português, uma língua que representa neste caso um não reconhecimento da complexidade do sujeito.

Poder elaborar pressupõe um trabalho em que o sujeito não considera os novos objetos identificatórios uma ameaça à sua identidade. As angústias atormentam e deixam esse que parte, inexoravelmente, descentrado de si mesmo.

Aparece, então, um sujeito que o tempo todo está em busca de si próprio na crença de uma possível unificação com o social e consigo mesmo. Uma unidade tentadora, segundo Koltai (2000), o "ego", o "nós", ou o "entre- nós"; uma identidade compacta que exclui os diferentes-de-mim, diferentes-de-nós, diferentes-do-consenso-do-entre-nós. Aquele que estranha e exclui parece acreditar na possibilidade de unidade, como também aquele que parte, antes de deixar sua cultura. $\mathrm{O}$ estrangeiro se dá conta da impossibilidade dessa unidade por preservar fundamentalmente na constituição de seu ego - uma singularidade que é impartilhável.

Portanto, é somente diante da tentativa de restituir a unidade para sempre perdida, ou que nunca existiu em nós, que faz sentido pensarmos a condição do estrangeiro.

A função que ocupa a sociedade de acolhimento diante de uma condição de estrangeiridade é notável. Mesmo escolhendo tratar dos componentes intrapsíquicos que podem ou não justificar essa condição numa migração temporária, como é o caso dos intercâmbios investigados em nossa pesquisa, reconhece-se que exista algo a mais que precisa ser esclarecido. Esse algo diz respeito à comunidade que não acolhe o estrangeiro. $\mathrm{O}$ não acolhimento diz respeito às características da sociedade, se ela é mais ou menos tolerante diante da diferença e, mais ainda, ao imaginário constituído a respeito desse estrangeiro.

Piret (2007), em seu seminário "Defender o estrangeiro?", trata a questão de defender o estrangeiro, e refere-se a uma experiência que aponta para a tentativa do sujeito de defender 
seu próprio desejo inconsciente. Nossa experiência nos ensina que defender o estrangeiro concreto é também defender a dimensão do desejo e do inconsciente. Defender a ideia que nós estamos todos "sujeitos" à uma instância estranha, externa e interna ao mesmo tempo, e que é a condição de nossa vida em sociedade. É indispensável manter em mente equivalências e compreender a verdadeira importância do desafio do reconhecimento da condição de estrangeiridade, sem atribuir ingenuamente responsabilidades aos grupos que por ventura venham a ser excluídos e sim, poder escutar a particularidade de cada caso. Podemos apenas afirmar que, em se tratando do migrante, antes de tudo está se tratando de um sujeito cuja formação conserva sua particularidade e garante a originalidade diante do que se dá pela transmissão do outro; sempre em relação ao que lhe é transmitido, o sujeito acrescenta à sua escuta, sua interpretação do que é vivido.

O que torna a experiência da estrangeiridade tão original é justamente aquilo que o sujeito acrescenta de si ao que lhe foi transmitido, transmissão essa em que nem tudo é passível de ser compartilhado com o outro. Na experiência da migração, o que vem do outro, o que não é familiar, marca o sujeito e transforma o ser com um saber acerca de algo que convoca-o a ser outro na medida em que guarda um pouco do que testemunhou. Pichon-Rivierè (1988) afirma que, diante da experiência das fronteiras e das culturas - é o caso de muitos - existe um tipo de dor nas identificações e um prazer em tratá-las e para isso precisamos escutar.

\section{Referências}

Enriquez, E. (1998). O judeu como figura paradigmática do estrangeiro. In C. Koltai (Ed.), O Estrangeiro (pp. 37-60). São Paulo: Ed. Escuta.

Freud, S. (1987). Conferências introdutórias à Psicanálise. Edição Standard Brasileira das Obras Completas de Sigmund Freud, v. XVII. Rio de Janeiro: Imago. (Trabalho original publicado em 1917)

Freud, S. (1987). O Estranho. Edição Standard Brasileira das Obras Completas de Sigmund Freud, vol. XVII. Rio de Janeiro: Imago. (Trabalho original publicado em 1919)

Kaës, R. (1998). Différence culturelle et souffrances de l'identité. Paris: Ed. Dunod.

Koltai, C. (2000). Politica e Psicanalise, O Estrangeiro. São Paulo: Ed. Escuta.

Métraux, J. C. (2011). Lutos Coletivos e criação social. Curitiba: Ed. UFPR.

Natahi, O. (2007). Dinâmica do aberto e problemática do estrangeiro. Rio de Janeiro: Editora Ágora.

Pichon-Rivière, E. (1998). O processo grupal. São Paulo: Martins Fontes. (Trabalho original publicado em 1983)

Piret, B. (2007). Defender o estrangeiro? In O seminário de psiquiatria, psicoterapia e cultura(s). Retrieved from http:// www.psf-port.com/spip.php?article14.

Sebben, A. (2000). Um estudo exploratório sobre Intercâmbio Cultural entre adolescentes brasileiros com a contribuição da Psicologia e da Educação Intercultural. (Unpublished master's thesis). Universidade Federal de Santa Catarina, Florianópolis.

Recebido em 26.02.2013

Primeira decisão editorial em 25.09.2013

Versão final em 21.10.2013

Aceito em 28.11.2013 